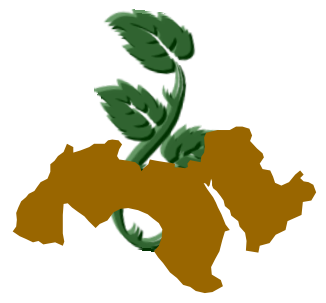

Arab Univ.

J. Agric. Sci., Ain Shams Univ., Cairo, 18(1), 31-37, 2010

\title{
DESIGNING AN INTEGRATED COMPUTER PROGRAM FOR VEGETABLE PRODUCTION IN THE KINGDOM OF SAUDI ARABIA
}

\author{
Abdullah A. Alsadon'; Abdulrahman A. Alazba²; Ibrahim M. Alshahwan; \\ Abdulrahman S. Aldawood ${ }^{3}$ and Safwat 0 . Khalil ${ }^{1}$ \\ 1. Department of Plant Production, 2. Department of Agricultural Engineering, 3. Department \\ of Plant Protection. \\ College of Food and Agricultural Sciences, King Saud University, P.O. Box 2460 Riyadh \\ 11451 Saudi Arabia. Alsadon@ksu.edu.sa
}

Keywords: Vegetable production, Saudi Arabia

\section{ABSTRACT}

Vegetable production provide great value in the agricultural production sector in the Kingdom of Saudi Arabia. Growers and agricultural engineers need a comprehensive database in Arabic language that can be available for use any time any where. Therefore, this research project was initiated. The computer program was developed using Visual Basic Net 2005 which is one of the advanced visual programming languages. We took into consideration easy usage and coherence between all program components. Main results include computer program with the data base, which includes: vegetable crops, diseases, insect pests and other pests that attacks vegetable crops, management tactics, cultural practices, irrigation requirements, planting dates, data search. Furthermore, field trips have been carried out to some vegetable farms in all the Kingdom regions. A digitized map of the Kingdom has been added to the program in addition to crop water and heat requirements. Various search capabilities have been developed in the program. After the completion of the program build up, verification trips have been carried out for five regions in the presence of farmers and extension specialists of the different directorate of the Ministry of Agriculture to test the accuracy of steps used in the program. A manual for the computer program as well as leaflet on program set up and usage have been included. It is recommended to make this program available at the internet and distribute copies to the Ministry of Agriculture and its directorates as well as farmers.

(Received July 20, 2009)

(Accepted September 7, 2009) 